\title{
Spatial and economic conditions of the solar energy use in single-family houses - a case study
}

\author{
Lukasz Kolendo*, Dorota Anna Krawczyk
}

Faculty of Civil Engineering and Environmental Engineering, Bialystok University of Technology, Bialystok, Poland

\begin{abstract}
The provisions in the European and Polish law oblige to increase the use of energy obtained from renewable energy sources. In order to meet these demands, it is necessary to take into account the singlefamily housing sector that has a significant energy potential. Among the unconventional heat sources that have gained the highest popularity, it is worthy to note installations using solar energy for instance to prepare DHW (domestic hot water) or be used in buildings' heating. It is also worth mentioning that this type of technical solutions can be successfully used as well in new as modernized old residential buildings.

Our paper discusses the problems associated with planning of solar installations with flat and vacuum solar collectors mounted on the roofs of the single-family buildings. During the analysis we used GIS\&T technology, multi-criteria decision support as well as detailed spatial data obtained by modern remote sensing techniques including airborne laser scanning.

The proposed methodology and tools were used on the example of the selected part of a single-family housing estate located in Bialystok.

The research focused on issues of the multi-criteria assessment of the assembly of use of roofs for solar collectors, including data on a solar potential, exposure, slope, surface and roofs' shape. Additionally, we took into account roof zones on being in a shadow caused by roof elements, roof infrastructure and high vegetation.

Based on the simulation results we analyzed possibility of plate and tube solar collectors' application that would provide warm water for 1-4 habitants of houses.

The results of our research showed high utility of the proposed methods in the field of spatial and economic assessment of the use of solar collectors in the single-family housing sector.
\end{abstract}

\section{Introduction}

Necessity of using alternative energy sources in order to reduce negative environmental changes is one of key principles mentioned in Polish and European Union law [1], [2], [3].

\footnotetext{
${ }^{*}$ Corresponding author: 1.kolendo@pb.edu.pl
} 
In most European countries, including Poland, significant awareness increase is seen in in terms of necessity of reduction of the energy consumption for heating, cooling and lighting purposes in building sector [4]. Furthermore a considerable amount of energy is yearly consumed by the building sector and major outcomes can be gathered to approach zero or nearly zero energy building by handling renewable energy technologies [5].

In this case it is worthy to note the housing sector that shows a significant potential in area of systems equipped with solar collectors for DHW preparation. Most companies that develop solar collectors offer ready to buy packages including solar panels, tanks, solar station and other necessary equipment dedicated to houses used by different number of users [6].

As shown in previous papers [7,8] usefulness of roofs depends on a variety of factors. The most important ones are solar radiation, slope and exposure of the roof, as well as its shape, however they differ in suitability. Assessment of the impact of the used evaluation criteria is possible when we use multi-criteria decision support methods. One of most popular methods is the AHP (Analytic Hierarchy Process) [9]. It us successfully used in many areas for example to find optimal locations. Moreover the AHP is applied to make decisions involving an assessment of multi-functional areas, technology innovations, security, and management or organizational problems [10].

The indicated factors determining the usefulness of roofs for the installation of solar installations are characterized by their spatial character, hence more and more popular in analysis are computer techniques referred as Geographic Information Science and Technology (GIS \& T) [11]. GIS \& T combined with data on geographical space obtained by means of the airborne laser scanning is currently widely used in the field of analysis related to possibility to install solar panels on roofs of buildings. This topic was discusses in papers [12-14].

The aim of this work is to discuss the spatial and economic conditions of the use of solar energy in the housing construction sector. The analysis is conducted for a part of real single-family housing estate.

\section{Study area}

A special-economic analysis was conducted for a selected part of Bialystok where singlefamily houses are located (fig. 1). This area, in administrative terms, belongs to Starosielce Płn and covers about 16.08 ha. Totally, 101 buildings are located in the study area, including 98 single-family houses and 3 public buildings. Within single-family houses, the twin houses are definitely dominant. The analysed estate is surrounded by a high plants and forests from north and east, the height of trees exceeds $22 \mathrm{~m}$. However, near buildings no trees are located that could cause shading of the roofs. 


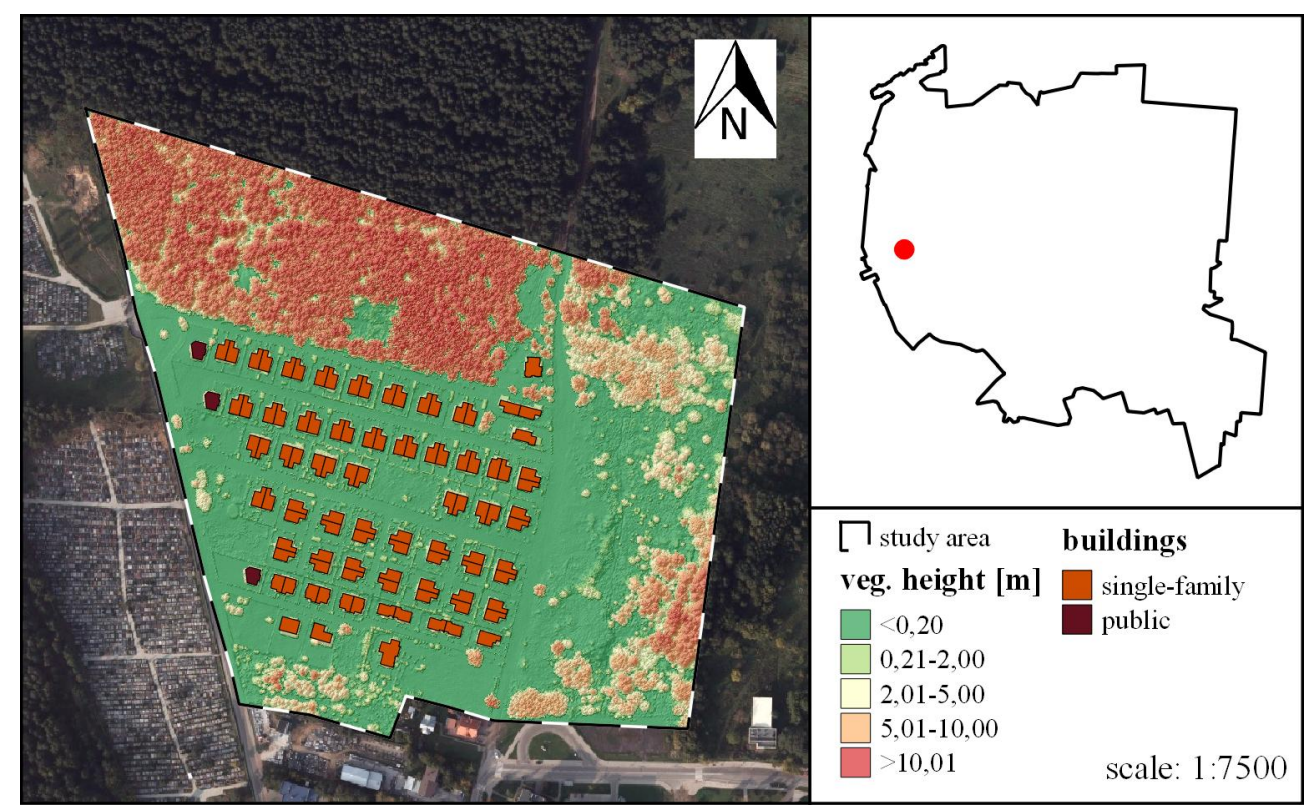

Fig. 1. Localization of study area in the Bialystok city and local conditions (source: own elaboration based on data gathered from National Geodetic and Cartographic Resources)

The analysed buildings, due to the fact that they were constructed at the same time, are characterized by a similar architectural style. The characteristic feature of the examined part of the buildings is a complexity of the roof geometry. In addition, the analysis of the available remote sensing materials allowed to conclude that there were roof windows and dormers. The fact could be an important factor limiting location of solar collectors on roofs.

\section{Materials and methods}

The research topic requires gathering and taking into account a wide range of data in order to create a spatial model of the studied structure. Geographical data was obtained from the National Geodetic and Cartographic Resources, delivered as:

- Classified point cloud acquired from Airborne Laser Scanning ALS (standard II - 12 $\left.\mathrm{pt} / \mathrm{m}^{2}\right)$,

-Building's footprints vector layer from topographic database BDOT10k,

- Aerial orthophoto with spatial resolution equal $10 \mathrm{~cm}$.

Based on the classified point cloud, digital elevation models were generated as Digital Terrain Model DTM, Digital Surface Model DSM and additional model estimated as the difference between DSM and DTM - Normalized Digital Surface Model nDSM. Models were prepared in software ArcGIS ESRI and Spatial Analyst extension. Moreover shaded surface models were developed with assumption of 1-direction and 8-direction lighting $[15,16]$. DSM data and r.sun model [17,18], implemented in open source software GRASS GIS, were used in calculations of solar potential of analysed roofs. Solar conditions was presented as a map of yearly sum od global irradiation incident od horizontal surface in real conditions (taking into account cloud cover influence). In calculations of annual solar radiation climatic data from [19] was used.

Finally, selected in described process, parts of roofs were analysed wherewithal a multicriteria analysis tools (the AHP method). It is worth mentioning that only the areas of residential buildings were analysed, whereas three public buildings were excluded. In the 
next stage, on the basis of the adopted scheme of a solar installation equipped with plate or tube vacuum solar collectors, the number of solar panels was selected, The assumption was that solar panels would ensure $100 \%$ of heating needs in a typical summer months. The number of inhabitants was in range from 1 to 4 people. The spatial assessment of the possibility of solar collectors on the roofs took into account shaded areas of roofs in the period of the greatest shading during the year - December 21.

As part of the economic analysis, the simple payback period of SPBT for a solar installation equipped with flat and tube solar collectors was estimated, as well as energy savings resulting from the installation solar panels. Savings were analysed in comparison to a few other energy sources for example electricity, oil, natural gas or coal.

\section{Determining of classes of roofs suitability}

The class of suitability of roofs was determined using 5 main criteria and 19 assessment sub-criteria (Table 1). The final usefulness of an analysed roof slope was determined as the sum of global importance. Four classes of suitability of the analysed areas were determined (Figure 2). Additionally our analysis applied the initial criterion - the minimum roof's slope area and all areas smaller than $10 \mathrm{~m}^{2}$ where not taken into account.

Table 1. Global weights (GW) and local weights (LW) of criteria and sub-criteria used during assessment of roofs suitability for solar systems (Source: own elaboration based on [7])

\begin{tabular}{|c|c|c|c|c|}
\hline Criteria & $\mathbf{G W}=\mathbf{L W}$ & Sub-criteria & LW & GW \\
\hline \multirow{4}{*}{ (A) solar potential } & \multirow{4}{*}{0.442} & $($ A. 1$)<750.00$ & 0.047 & 0.021 \\
\hline & & (A.2) $750.01-800.00$ & 0.085 & 0.037 \\
\hline & & (A.3) $800,01-825,00$ & 0.269 & 0.119 \\
\hline & & (A.4) $>825,01$ & 0.599 & 0.265 \\
\hline \multirow{4}{*}{$\begin{array}{l}\text { (B) location in terms of } \\
\text { cardinal directions }\end{array}$} & \multirow{4}{*}{0.299} & (B.1) N, NW, NE & 0.047 & 0.014 \\
\hline & & (B.2) W, E & 0.085 & 0.025 \\
\hline & & (B.3) SE, SW & 0.269 & 0.081 \\
\hline & & (B.4) S & 0.599 & 0.179 \\
\hline \multirow{4}{*}{ (C) slope of roofs } & \multirow{4}{*}{0.129} & $($ C. 1$)<20.00$ & 0.097 & 0.012 \\
\hline & & (C.2) 20.01-30.00 & 0.262 & 0.034 \\
\hline & & (C.3) 30.01-45.00 & 0.573 & 0.074 \\
\hline & & $($ C. 4$)>45.01$ & 0.068 & 0.009 \\
\hline \multirow{4}{*}{ (D) area of roofs } & \multirow{4}{*}{0.090} & $(D .1)<20.00$ & 0.064 & 0.006 \\
\hline & & (D.2) 20.01-30.00 & 0.124 & 0.011 \\
\hline & & (D.3) 30.01-40.00 & 0.276 & 0.024 \\
\hline & & (D.4) $>40.01$ & 0.536 & 0.048 \\
\hline \multirow{3}{*}{$\begin{array}{l}\text { (E) coeficient of a roof } \\
\text { shape }\end{array}$} & \multirow{3}{*}{0.040} & $($ E. 1$)<3.00$ & 0.064 & 0.003 \\
\hline & & (E.2) 3.01-6.00 & 0.237 & 0.010 \\
\hline & & $($ E. 3$)>6.01$ & 0.699 & 0.028 \\
\hline
\end{tabular}

The conducted analysis of roofs suitability showed the numerical dominance of the tracts classified as unsuitable for the assembly of solar installations. Such case occurred in 471 areas, that constitutes $60.23 \%$ of all considered parts. In this group there were areas 
that did not meet the requirements related to the minimum area criterion. A large number of instances of this type are dictated by a significant degree of complexity of roof geometries occurring in the studied area. Among all 782 areas covered by the analysis, 160 belong to classes characterized by low and very low usefulness. This group includes roof slopes with worse exposure (usually northern), which results in worse solar conditions, than southern rooflines. The smallest number of areas had a moderate suitability for installation of solar installations ( 7 such cases). Within the analysed part of the housing estate there were 144 areas with the highest degree of usability in the area of assembling solar systems (18.41\%).

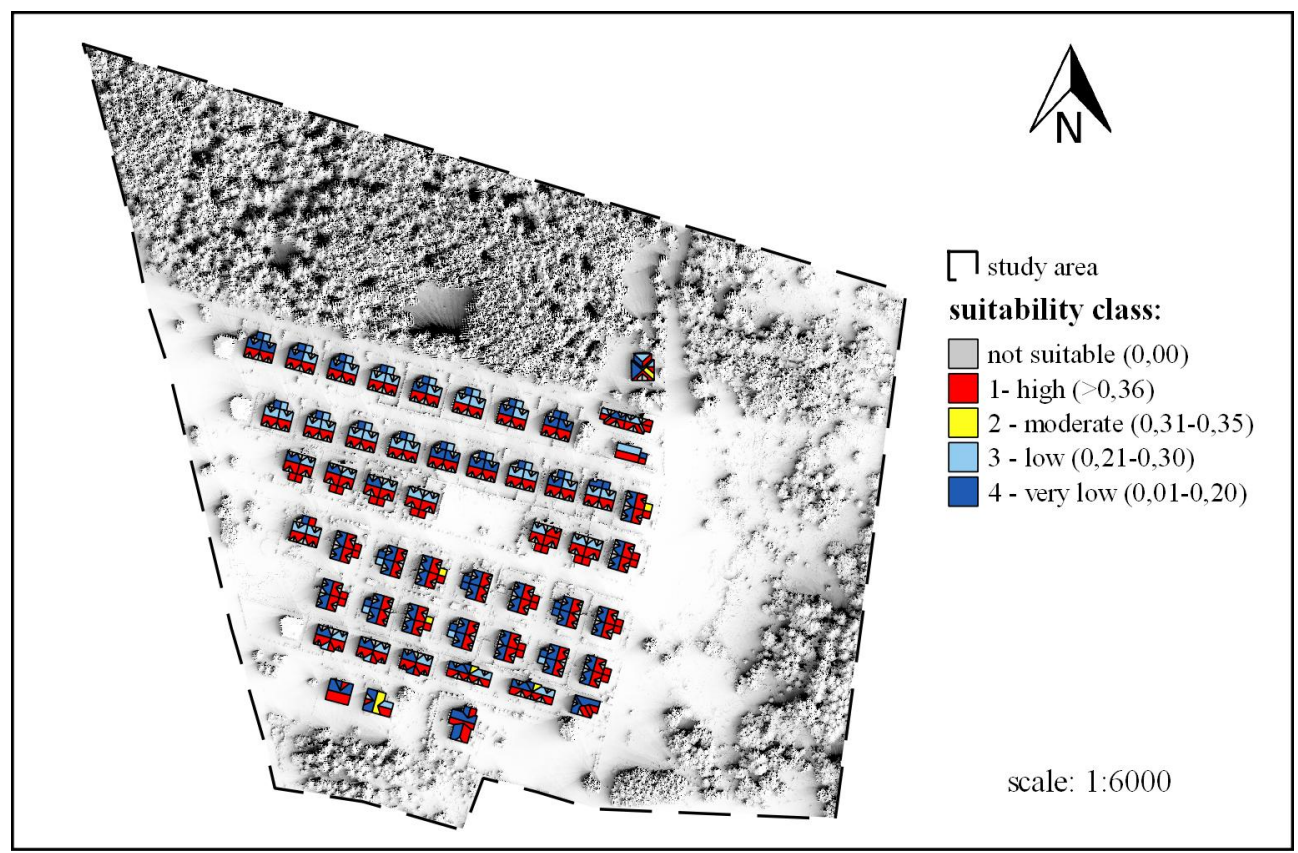

Fig. 2. Spatial distribution of suitability classes of particular roof parts for mounting solar installations (source: own elaboration based on data gathered from National Geodetic and Cartographic Resources)

\section{Spatial and economic factors in terms of solar energy use in considered roofs}

For the further analysis, only the areas with the highest usability class for solar installations were taken into account. We analysed if there was a possibility to install solar panels on roofs that would provide $100 \%$ of thermal needs for hot water purposes in summer season. In table 2 necessary number of solar collectors, depending on the variant (number of users) was shown.

Table 2. Required number of solar collectors (panel or tube) depending on number of habitants (Source: [8])

\begin{tabular}{|c|c|}
\hline Number of users & Number of solar panels with $\mathbf{2 m}^{\mathbf{2}}$ area \\
\hline 1 & 1 \\
\hline $2-3$ & 2 \\
\hline $4-5$ & 3 \\
\hline
\end{tabular}

During the analysis of possibility to install solar collectors on roofs of houses, we took into account problem of the shading caused by the roof elements and infrastructure (e.g. flue gas chimneys). The map of shading was generated on the basis of the DSM layer 
taking into account the position of the Sun on December 21 at 12.00, when the shadow is the longest within a year. Taking into account the geographical location of Bialystok, the position of the Sun was adopted, characterized by the following parameters: the altitude of the Sun $-13.13^{\circ}$, the azimuth - $188.1 \mathrm{~W}$ (Figure 3).

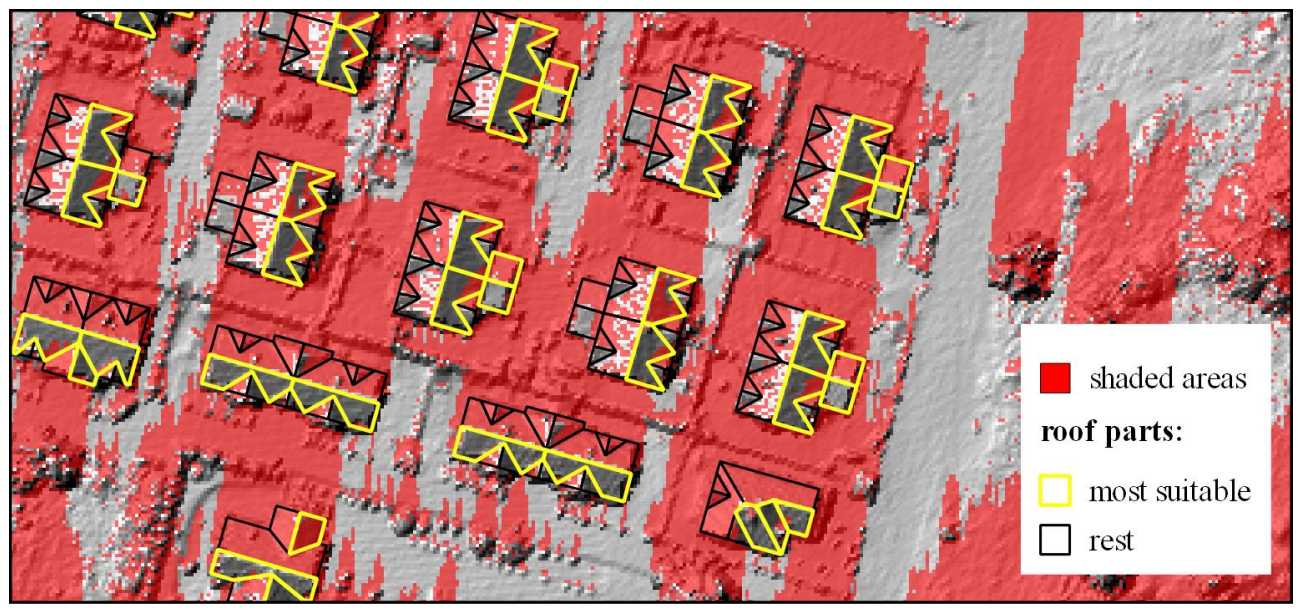

Fig. 3. Spatial distribution of suitability classes of particular roof parts for mounting solar installations (source: own elaboration based on data gathered from National Geodetic and Cartographic Resources)

The areas of maximum shading (Figure 3) were considered as an auxiliary source of information in the process of collector location on the roofs of the analysed buildings. The spatial distribution of shading of the roofs corresponds with the results of the method used to determine the usefulness of roofs. Parts of roof identified as the most useful are generally free from the shading effect. At the same time, among the most useful areas it is possible to find areas partly remaining in the shade, however, the maximum shades that were analysed should not influence the arrangement of solar panels [6]. Main assumptions regarding the distance between collectors and other elements were as follows: - at least $0.10 \mathrm{~m}$ spacing between solar panels,

- $1.00 \mathrm{~m}$ distance between solar panel and any edge of the roof.

The analysis did not take into account small elements limiting the solar panel foundation as for instance ventilation chimneys. Moreover we assumed that there were no existing solar installations.

Taking into account the assumed initial assumptions, it was found that within the area with the highest solar usability, it was possible to install 3 solar panels, providing $100 \%$ coverage of thermal needs for DHW installations in summer season, what is recommended in case of houses with 4 people.

Therefore, solar systems equipped in 3 solar collectors was considered in two variants: a) tube collectors,

b) pipe collectors.

To estimate solar energy gains from 3 solar panels in climatic conditions of Bialystok we used methodology described in [20]. Result were presented in figure 4. 


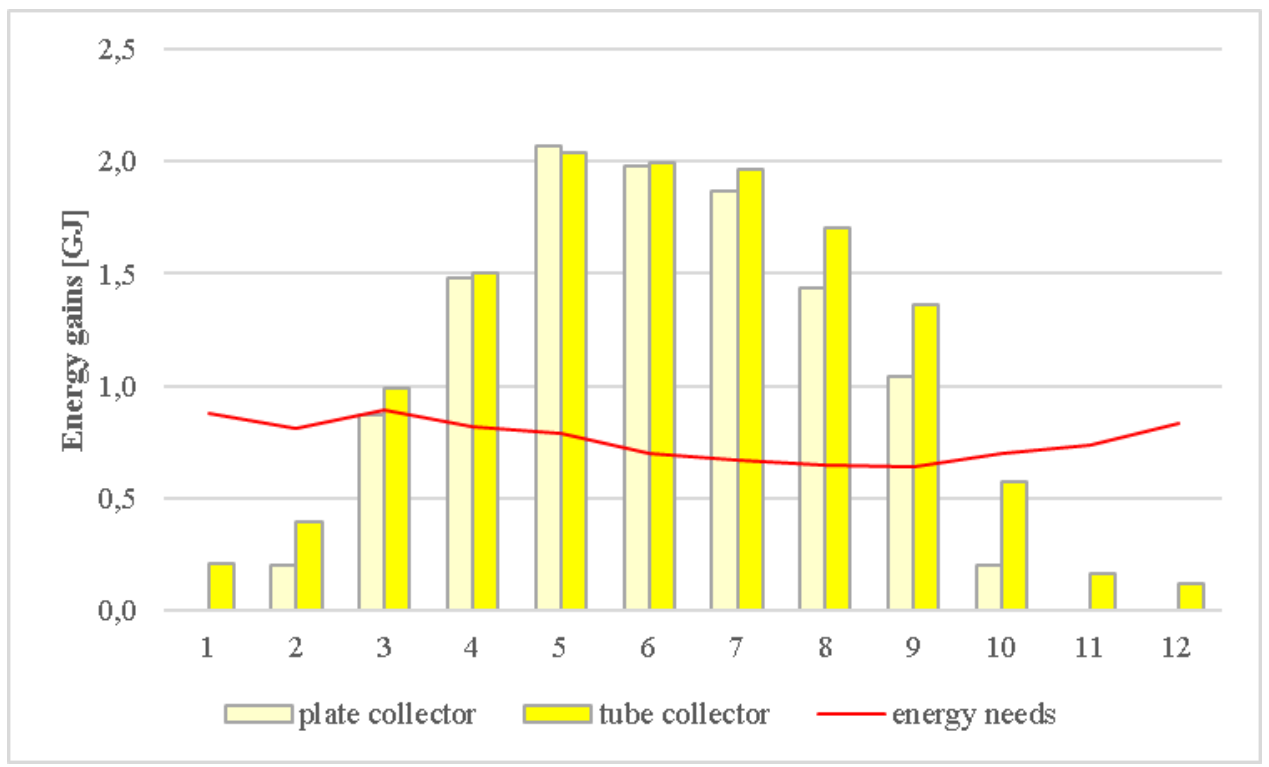

Fig. 4. Total solar energy gains from 3 collectors [source: own elaboration based on [20])

As presented in fig. 4 the solar contribution in a total energy demand is higher in case of tube vacuum collectors. In period between April and September both types of collectors can deliver amount of energy higher than energy needs for DHW are. However from October to February solar contribution is from 0 to $28.6 \%$ for flat-plane collectors and from 14,5 to $81,4 \%$ for vacuum pipe ones. In March solar gains from tube collectors exceed heat needs while plate collectors can deliver $97,8 \%$ of heat needed. Annually, tube collectors share in heat delivered to DHW was estimated as $84 \%$, while for plate collectors $65 \%$.

Solar collectors should reduce energy needs for DHW in a house by 5,96 GJ per year in case of plate collectors and 7,63 GJ per year while tube collectors are used. According to our assumption that all houses in the estate have four habitants energy savings for the analysed group of buildings was estimated as 584,08 GJ for systems with solar plate collectors and 747,74 GJ for installations with tube collectors.

We estimated potential savings that would appear as a result of the installation solar collectors in the analysed dwellings, compared with variants with a use of conventional energy sources in DHW systems (Figure 5). Results of our analysis showed that maximum savings would be obtained in case of pipe collector installations replacing electrical heaters (112 327.25 PLN per year). Apart of electric energy sources for the preparation of hot water also installation of solar collects in buildings that use LPG would result in high savings. On the other hand the smallest savings would appear in houses where existing installations are using wood, pellets, coal and natural gas.

Taking into account the current costs of DHW preparation in various installations using conventional energy sources, the SPBT period for installation was estimated in a range between 4 and 19 years, depending on fuel type, selection of manufacture, percentage of grant received to refund part of expenses. 


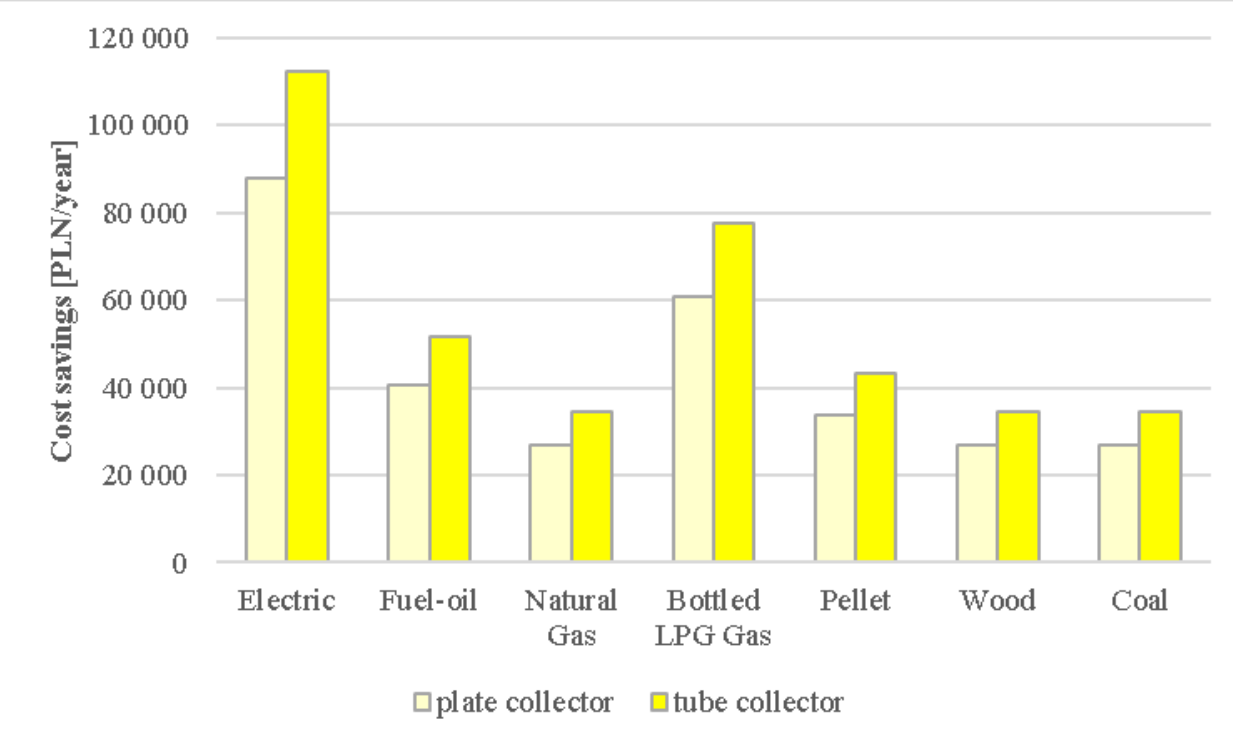

Fig. 5. Comparison of costs savings [PLN/year] as a result of modernization system for HDW preparation with installations including solar collectors: plate and tube (source: own elaboration based on $[20])$

\section{Conclusions}

Results of the conducted analyses show that the use of solar energy in the field of DHW preparation in houses depends on many factors like area and shape of roofs, number of users, house location or additional heat source used. During analysis for towns or estates the methodology developed to determine the usefulness of roofs for the installation of solar systems allows for automation of this type of issues.

Analysis showed that in summer (April-September) plate and tube collectors can deliver more energy than energy needs for DHW are. In colder months (October-February) solar contribution reaches $28.6 \%$ for flat-plane collectors and up to $81,4 \%$ for vacuum pipe ones. In March solar gains from tube collectors exceed heat needs while plate collectors can deliver $2.2 \%$ less than theoretical heat needs. Annual comparisons showed higher heat gains from tube collectors, than plate ones.

SPBT period for installation of solar panels was estimated in a range between 4 and 19 years, depending on fuel type trade up to collectors or amount of grant possible to receive to refund part of expenses.

\section{References}

1. Directive 2009/28/EC of the European Parliament and of the Council of 23 April 2009 on the promotion of the use of energy from renewable sources.

2. Polish Regulation from 20 February 2015 on renewable Energy sources. (In Polish Dz. U. 2015 poz. 415).

3. Energy Policy of Poland till 2030 from 10 November 2009. Warszaw (In Polish).

4. D.A. Krawczyk, A. Rodero Serrano, Analysis of an Energy Consumption for Heating and Cooling Depending on the Buildings Location. COW 3, 118-120 (2016) (In Polish). 
5. F. Montoya, M. Aguilera, F. Manzano-Agugliaro, Renewable energy production in Spain: A review. Renew. Sust. Energ. Rev. 33, 509-531 (2014).

6. M. Żukowski, P. Radzajewska, Optimal distance between solar collectors. COW 1, 811 (2016) (In Polish).

7. Ł.Kolendo, D.A. Krawczyk, Methodology of assesement of roofs usage for solar instalations with GIS data 3D. COW 10, 400-405 (2016) (In Polish).

8. Ł.Kolendo, D.A. Krawczyk, Designing Solar Installations by Using GIS - a Case Study COW 1, 20-23 (2017) (In Polish).

9. T. Saaty, The Analytic Hierarchy Process: Planning. Priority Setting. Resource Allocation. McGraw-Hill (1980).

10. A. Detrich, Application of analytic hierarchy (AHP) methods to assess the level of technical safety of gas pipelines. Naf.-Gaz 12, 1123-1131 (2010) (In Polish).

11. J. Kozak, Jerzy Bański: What type of geography? - conditions and futher predictions: discussion. Przegl. Geogr. 85(3), 455-461 (2013) (In Polish).

12. R. Kassner, W. Koppe, T Schüttenberg, T. Bareth, Analysis of the solar potential of roofs by using official LiDAR data.. Int. Arch. Photogramm.37, 399-404 (2008).

13. L.K. Wiginton, H.T. Nguyen, J.M. Pearce, Quantifying Rooftop Solar Photovoltaic Potential for Regional Renewable Energy Policy. Comput. Environ. Urban. 34, 345357 (2010)

14. K. Suomalainen, V. Wang, B. Sharp. Rooftop solar potential based on LiDAR data: Bottom-up assessment at neighbourhood level. Renew. Energ. 111, 463-475 (2017).

15. K. Žiga, Z. Klemen, K. Oštir, Application of Sky-View Factor for the Visualization of Historic Landscape Features in Lidar-Derived Relief Models. Antiquity 85, 263-273 (2011).

16. K. Zakšek, K. Oštir, Ž. Kokalj, Sky-View Factor as a Relief Visualization Technique. Rem. Sens. 3, 398-415 (2011).

17. J. Hofierka. Direct solar radiation modelling within an open GIS environment. Proceedings of the Joint European GIS Conference, 575-584 (1997).

18. J. Hofierka, M. Š́ri, The solar radiation model for open source GIS: implementation and applications. Proceedings of the Open Source GIS - GRASS Users Conference (2002).

19. P.G. Narowski, Climatic data for Energy calculations in civil stuctures. COW 11, $22-$ 27 (2006) (In Polish).

20. D.A. Krawczyk, A. Rodero Serrano, Ł. Kolendo. Analysis of solar collectors' use in a single family house in Poland and Spain - a case study. 2018, IOP Conference Series: Earth and Environmental Science (EES)-accepted . 